\title{
Mutation-in-Brief
}

\section{H62L Mutation of CYP21A2 Identified in the Non-classical Form of 21-Hydroxylase Deficiency}

\author{
Keisuke Nagasaki ${ }^{1}$, Takeshi Usui ${ }^{2}$, Tadashi Asami ${ }^{3}$, Yohei Ogawa ${ }^{1}$, \\ Toru Kikuchi ${ }^{1}$, and Makoto Uchiyama ${ }^{1}$ \\ ${ }^{I}$ Division of Pediatrics, Department of Homeostatic Regulation and Development, Niigata University Graduate \\ School of Medicine and Dental Sciences, Niigata, Japan \\ ${ }^{2}$ Clinical Research Institute Center for Endocrine and Metabolic Diseases, National Hospital Organization, Kyoto \\ Medical Center, Kyoto, Japan \\ ${ }^{3}$ Faculty of Nursing, Social Welfare, and Psychology, Department of Nursing, Niigata Seiryo University, Niigata, \\ Japan
}

\section{Introduction}

Neonatal mass screening for congenital adrenal hyperplasia (CAH) has been performed in Japan since 1989. Steroid 21-hydroxylase deficiency (21-OHD) represents about $95 \%$ of $\mathrm{CAH}$ patients and is traditionally divided into three forms, severe classical salt-wasting (SW), simple virilizing (SV) and the milder non-classical (NC) form. Very rare cases of the NC form have been detected because of elevated 17-hydroxyprogesterone (17-OHP) levels at neonatal mass screening in Japan (1). The estimated rate of detection of the $\mathrm{NC}$ form by mass screening seems to be low $(1: 1,100,000)(1)$. This disease is caused by deletions or mutations of CYP21A2. In Japan, the P30L mutation appears more likely to be associated with Japanese NC patients (1). Here, we report a rare

Received: April 1, 2009

Accepted: May 13, 2009

Correspondence: Dr. Keisuke Nagasaki, Division of Pediatrics, Department of Homeostatic Regulation and Development, Niigata University Graduate School of Medicine and Dental Sciences, 1-757 Asahimachi, Niigata 951-8510, Japan

E-mail: nagasaki@med.niigata-u.ac.jp
H62L mutation with the NC form in a Japanese 21-OHD patient.

\section{Case Report}

The patient was a female who was the second child of non-consanguineous parents and was born at 40 wk gestation with a body weight of $3,408 \mathrm{~g}$ after an uncomplicated pregnancy. High levels of 17-OHP were detected by neonatal screening for 21-OHD, and she was referred to our department at $27 \mathrm{~d}$ of age. Her 17-OHP level in dried blood was $15.21 \mathrm{ng} / \mathrm{ml}$ (cut off limit: 10 $\mathrm{ng} / \mathrm{ml}$ ) without initial steroid extraction from the filter paper sample at $5 \mathrm{~d}$ of age and $7.8 \mathrm{ng} /$ $\mathrm{ml}$ (cut off limit: $2 \mathrm{ng} / \mathrm{ml}$ ) with steroid extraction at $20 \mathrm{~d}$ of age. She did not show any signs of 21-OHD, such as skin pigmentation, poor weight gain, vomiting or virilization of external genitalia except that her clitoral size was at the upper limit for normal (6 mm length, $5 \mathrm{~mm}$ width). Her serum 17-OHP level was continuously elevated $(74 \mathrm{ng} / \mathrm{ml}$ at $27 \mathrm{~d}$ of age and $110 \mathrm{ng} / \mathrm{ml}$ at $45 \mathrm{~d}$, respectively). Serum Na, K and plasma renin activity were normal $(139 \mathrm{mEq} / \mathrm{l}, 5.9 \mathrm{mEq} / \mathrm{l}$ and $4.9 \mathrm{ng} / \mathrm{ml} / \mathrm{h}$, respectively). Her plasma ACTH (204 pg/ml) and serum androstendione (2.9 ng/ 
Codon 62



Father

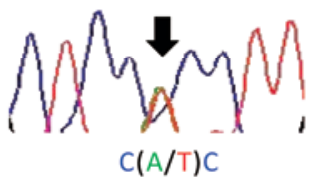

Mother



C A C
Exon 6
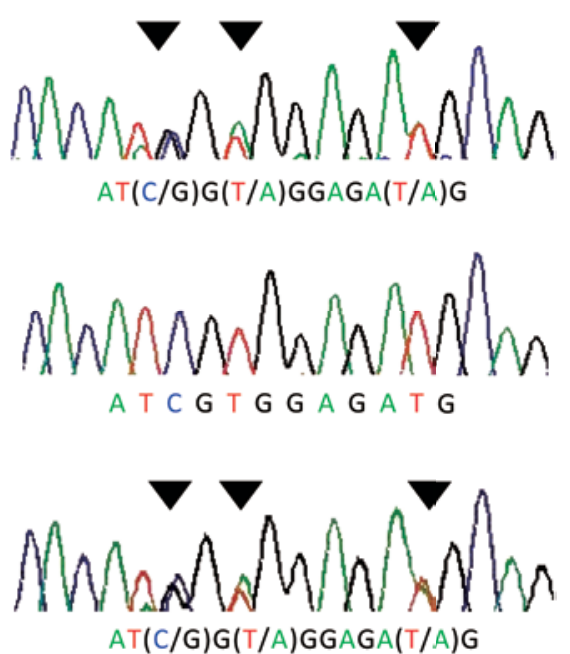

Fig. 1 An electrochromatogram showing compound heterozygous mutations (c.185A>T, p.H62L) denoted by arrows and E6 cluster mutations denoted by arrowheads.

$\mathrm{ml}$; reference range 0.15-1.5) levels were elevated. Based on the persistent elevations of serum 17OHP, ACTH and androstendione, the patient was diagnosed as having the NC form of 21-OHD. After obtaining informed consent, direct sequencing was performed for CYP21A2 using leukocyte genomic DNA from this patient and her parents in accordance with previously reported methods (2). DNA analysis demonstrated an H62L mutation in exon 1 derived from her father and E6 cluster mutations (I236M, V237E, M239K) from her mother (Fig. 1).

\section{Discussion}

We identified the first Japanese patient with the NC form of 21-OHD, and this patient had a rare $\mathrm{H} 62 \mathrm{~L}$ mutation of CYP21A2. So far, mutation of $\mathrm{H} 62 \mathrm{~L}$ has been described in only 16 other ethnic patients in the NC or SV form of 21-OHD $(3,4)$. In most of these patients, H62L has been associated on the same allele with another mild mutation, such as P30L or P453S (H62L+P30L or H62L+P453S), and only two patients with the NC form have had an isolated
H62L mutation. The genotype of these two patients was a combination of $\mathrm{H} 62 \mathrm{~L}$ and gene deletion or I172N. Functional analysis revealed that the residual enzymatic activity of $\mathrm{H} 62 \mathrm{~L}$ showed values of 20 to $60 \%$ as well as that of $\mathrm{P} 453 \mathrm{~S}$ or V281L, which are responsible for the $\mathrm{NC}$ form $(3,4)$. On the other hand, the E6 cluster is classified as a null mutation. These data indicated that the combination of H62L in one allele and deletion/mutations on the other allele is related to the NC form. Therefore, the phenotype of our patient is in agreement with the genotype of the combination of H62L and E6 cluster mutations. However, it is of note that our patient's basal 17-OHP level was plotted between the $\mathrm{SV}$ and $\mathrm{NC}$ forms in the nomogram reported by Wilson RC et al. (5). As mentioned, $\mathrm{H} 62 \mathrm{~L}$ mutation is often associated on the same allele with a mild mutation; however, our sequence analysis did not find any other mutation than H62L in the allele from the father. Thus, the exact reason of this discrepancy between the phenotype and 17-OHP level is unknown. Further accumulation of data for Japanese 21$\mathrm{OHD}$ patients carrying the H62L mutation is 
needed to clarify this point.

In conclusion, we reported a rare $\mathrm{H} 62 \mathrm{~L}$ mutation of CYP21A2 in a patient with the $\mathrm{NC}$ form 21-OHD.

\section{References}

1. Tajima T, Fujieda K, Nakae J, Mikami A, Cutler GB Jr. Mutations of the CYP21 gene in nonclassical steroid 21-hydroxylase deficiency in Japan. Endocr J 1998;45:493-7.

2. Usui T, Nishisho K, Kaji M, Ikuno N, Yorifuji T, Yasuda $\mathrm{T}$, et al. Three novel mutations in Japanese patients with 21-hydroxylase deficiency. Horm Res 2004;61:126-32.
3. Soardi FC, Barbaro M, Lau IF, Lemos-Marini SH, Baptista MT, Guerra-Junior G, et al. Inhibition of CYP21A2 enzyme activity caused by novel missense mutations identified in Brazilian and Scandinavian patients. J Clin Endocrinol Metab 2008;93:2416-20.

4. Menassa R, Tardy V, Despert F, Bouvattier-Morel C, Brossier JP, Cartigny M, et al. p.H62L, a rare mutation of the CYP21 gene identified in two forms of 21-hydroxylase deficiency. J Clin Endocrinol Metab 2008;93:1901-8.

5. Wilson RC, Mercado AB, Cheng KC, New MI. Steroid 21-hydroxylase deficiency: genotype may not predict phenotype. J Clin Endocrinol Metab 1995;80:2322-9. 